\title{
Decision Support System in Software Development: Safety Hazards Early Warning and Treatments in Mine Main Ventilator
}

\author{
Xiao-Yan Gong, Shao-Ni Qin, Wan-Ying Jiao, Min-Xian Zhao, Xin Gao, He Xue \\ School of Mechanical Engineering, Xi'an University of Science and Technology, Xi'an, Shaanxi 710054,China \\ E-mail: gongxymail@163.com,623778495@qq.com
}

\begin{abstract}
In view of the current situation that mine main ventilator can only monitor parameters, can not identify types and causes of the fault, the expert decision support system for safety hidden danger of main ventilation was researched and developed. On the basis of investigating safe operation condition, as well as analyzing and collecting fault cases of main ventilator in major domestic coal mines, the main types of safe hazards and the warning judgment criteria were determined. Then the methods of safety evaluation and treatment strategies were analyzed, and function model and information database system of expert knowledge representation which based on production rules were established. The overall framework of the decision support system and the software interface were designed and developed. This operational software has been installed and applied in Nanliang coal mine currently, the preliminary operating results are favorable and have achieved the desired objectives.
\end{abstract}

Keywords-mine main ventilator; software development; safety hazards warning; safety evaluation; decision support system

\section{INTRODUCTION}

The safe and efficient operation of main ventilator system in coal mine is the basic guarantee of the ventilation safety and economic operation. But at present there are still a lot of main ventilator security hidden hazards ${ }^{[1]}$. Due to complex structures, various fault reasons, and random uncertainty and fuzziness of main ventilator, judging the safety hidden danger of the main ventilator was a difficult problem. At present, safety operation manage in mine main ventilator mainly stays only in the monitoring parameters, and can not identify the fault types and the reasons ${ }^{[2]}$. For example, researchers like Lim K B , Yao Yun ${ }^{[3]}$ and $\mathrm{He}$ Yong-hui [4] etc, their research works about the main ventilator monitoring system lack of the early warning concerning safety hidden hazards, causes and countermeasures. In this paper, the expert decision support system for safety hidden danger of main ventilation was researched and developed, an expert-generated rule method [5] of mine main ventilator types of hidden safety hazards, early warning criteria, safety assessment and expert treatment methods were analyzed.The functional model of the system was established, and the overall framework and the software interface of the system based on WEB and $\operatorname{IDSS}^{[6]}$ are designed and developed, can reduce security risks blind to diagnosis and technical difficulties, improve the main ventilator's safety informative and intelligent management level.

\section{BASIC FRAME DESIGN OF THE SYSTEM}

Based on the research of Shenhua Ningxia Coal Industry Group Co.,Ltd., Shaanxi Zhongneng Coalfield Co.,Ltd. and other major coal mine in terms of main ventilator operation, the main types of security hidden hazards were extracted, and their logical relations are analyzed, and the fault tree model was established.

\section{A. Function Module}

The coal mine main ventilator fault tree model in various types of hidden safety trouble warning judgment of measured parameters and symptom, systems and components evaluation method and experts' countermeasures were analyzed. The theory and method of security hidden danger warning, safety evaluation and treatment countermeasures based on production rules were established, thereby setting up the security hidden danger warning, safety evaluation and treatment of the demand of the system function model to meet customer demand. It mainly includes system help, real-time early warning and countermeasures, artificial early warning and countermeasures, safety evaluation and early warning, warning records, analysis reports and other functional modules, shown as Fig.1.

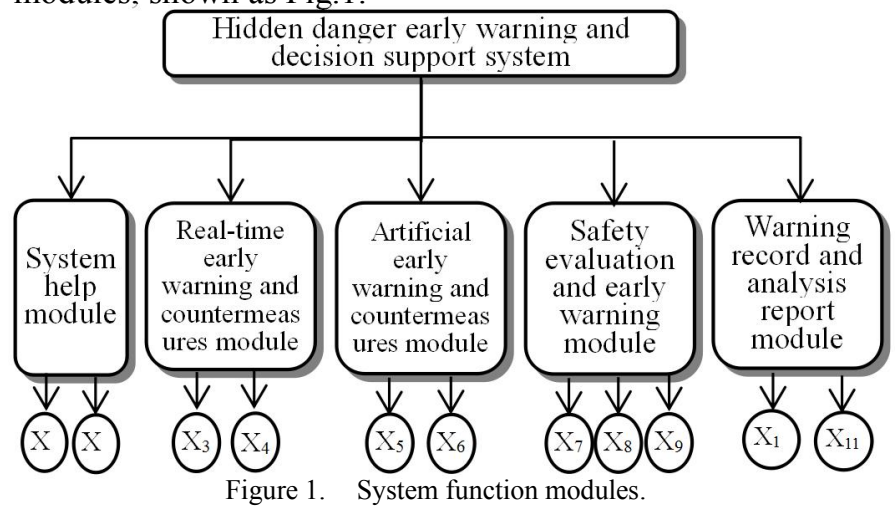

$\mathrm{X}_{1}$.System description and help file access; $\mathrm{X}_{2}$.Document inspection of coal mine management standard; $X_{3}$. Real time operating parameters and working condition curve display; $\mathrm{X}_{4}$.Early warning and treatment countermeasures; $\mathrm{X}_{5}$. Early warning and treatment strategy case database query; $\mathrm{X}_{6}$. Manual daily check list call and check; $\mathrm{X}_{7}$.System security evaluation and early warning display; $\mathrm{X}_{8}$.Stability and economic evaluation and early warning display; $\mathrm{X}_{9}$.Parts of the proportion of hidden dangers; $\mathrm{X}_{10}$.Early warning information input and display; $\mathrm{X}_{11}$. Analysis of the proposed report calls and display.

The system help module provides the help information, production management rules and regulations for the users; 
Real-time warning and countermeasure module contains the security risks in operating parameters in real time, real-time prediction and treatment; Artificial warning and countermeasure module contains safety artificial risks early warning method and processing method of query, management and maintenance methods; Safety evaluation and early warning module contains system safety calculation, evaluation and early warning model, parts' risk degree calculation method; Early warning record and analysis report module includes a fault record entry shows and accident analysis report.

\section{B. Overall Framework Of System Based On Idss And Web}

According to the above models, the intelligent decision support system (IDSS) was used to call and control the safety hazard warning and handling process of the main ventilation. Selecting and calling an early warning model class from the system model library in the light of users' different demands, and by calling the system knowledge base and database information to display the task. Finally, achieving the role of intelligent decision support system. The web information architecture is used to establish the whole framework of system information, which is embedded into the web portal. WEB browser layer contains mine leader PC terminal, the mobile terminal and mine main ventilation monitoring station. WEB server layer integrates five functional modules, namely the system help module, real-time warning and countermeasure module, safety evaluation and early warning module, artificial early-warning and countermeasure module and early warning record and analysis report module. WEB information layer is used to store the knowledge base, model base and database. and can be called, modified and supplemented at any time. The overall information architecture of the system is shown in Fig. 2.

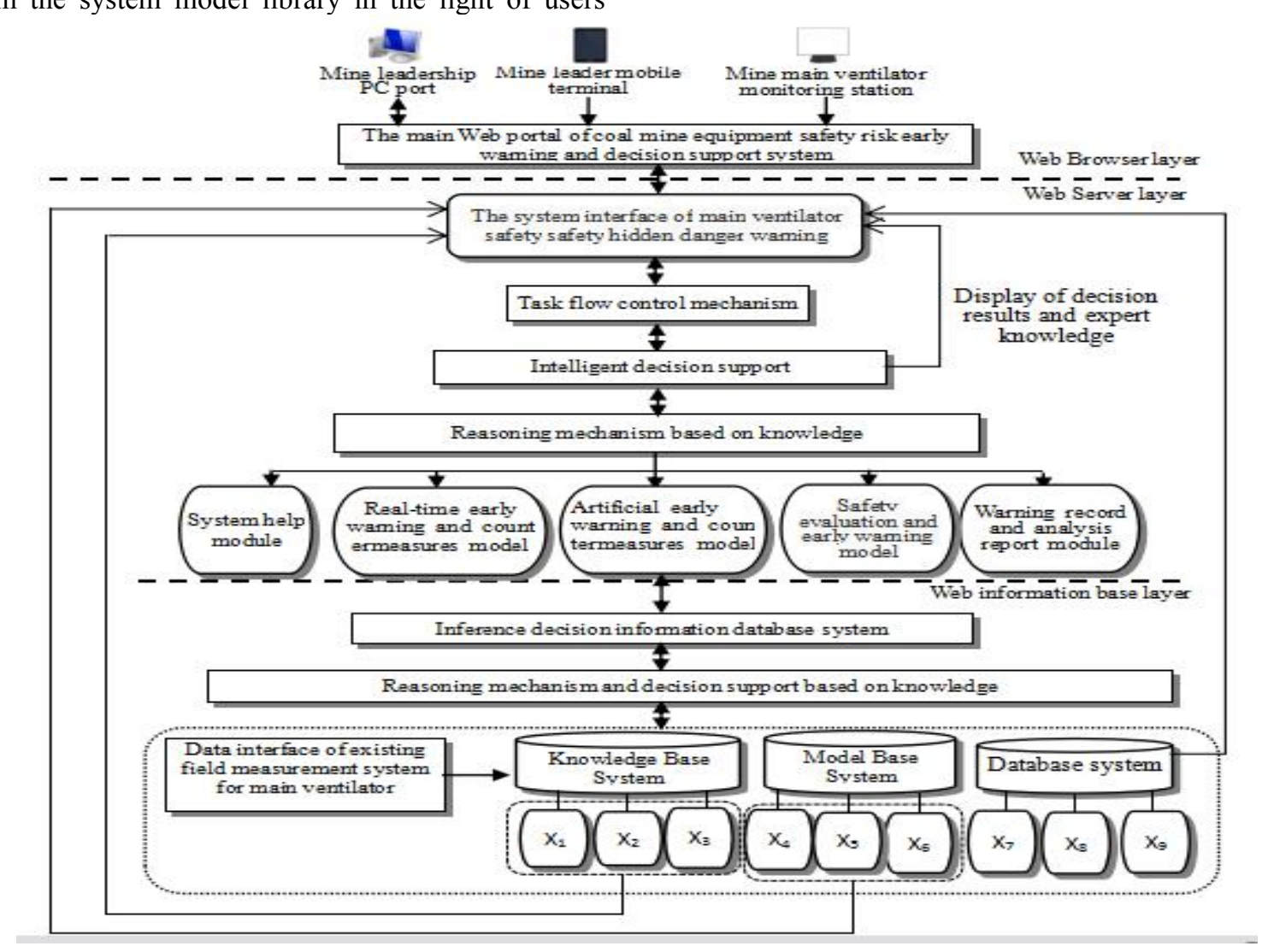

Figure 2 The overall information architecture of the system based on IDSS and WEB.

NOTE: $\mathrm{X}_{1}$.Early warning and countermeasure case base; $\mathrm{X}_{2}$. Document knowledge base; $\mathrm{X}_{3}$.Decision knowledge base; $\mathrm{X}_{4}$. Early warning and countermeasure model base; $\mathrm{X}_{5}$.Evaluation and early warning model base; $\mathrm{X}_{6}$.Equipment management model base; $\mathrm{X}_{7}$.Early warning and countermeasure database; $\mathrm{X}_{8}$.Evaluation and early warning database; $\mathrm{X}_{9}$.Equipment management database.

\section{SYSTEM DESIGN AND IMPLEMENTATION}

\section{A. User Requirement Analysis}

The system's user activity analysis describes security early warning and decision making support of the mine main ventilator in the running process of the system task scheduling, analysis, storage or data exchange activities, and the sequence of these activities are performed (as Fig.3 shows).

\section{B. System Interface Design}

The user interface and call process of the system software have been analyzed, and the design scheme of the system software is presented. The main interface diagram of the system software design is shown in Fig. 4. The design of 
each functional area on the main interface is as follows:

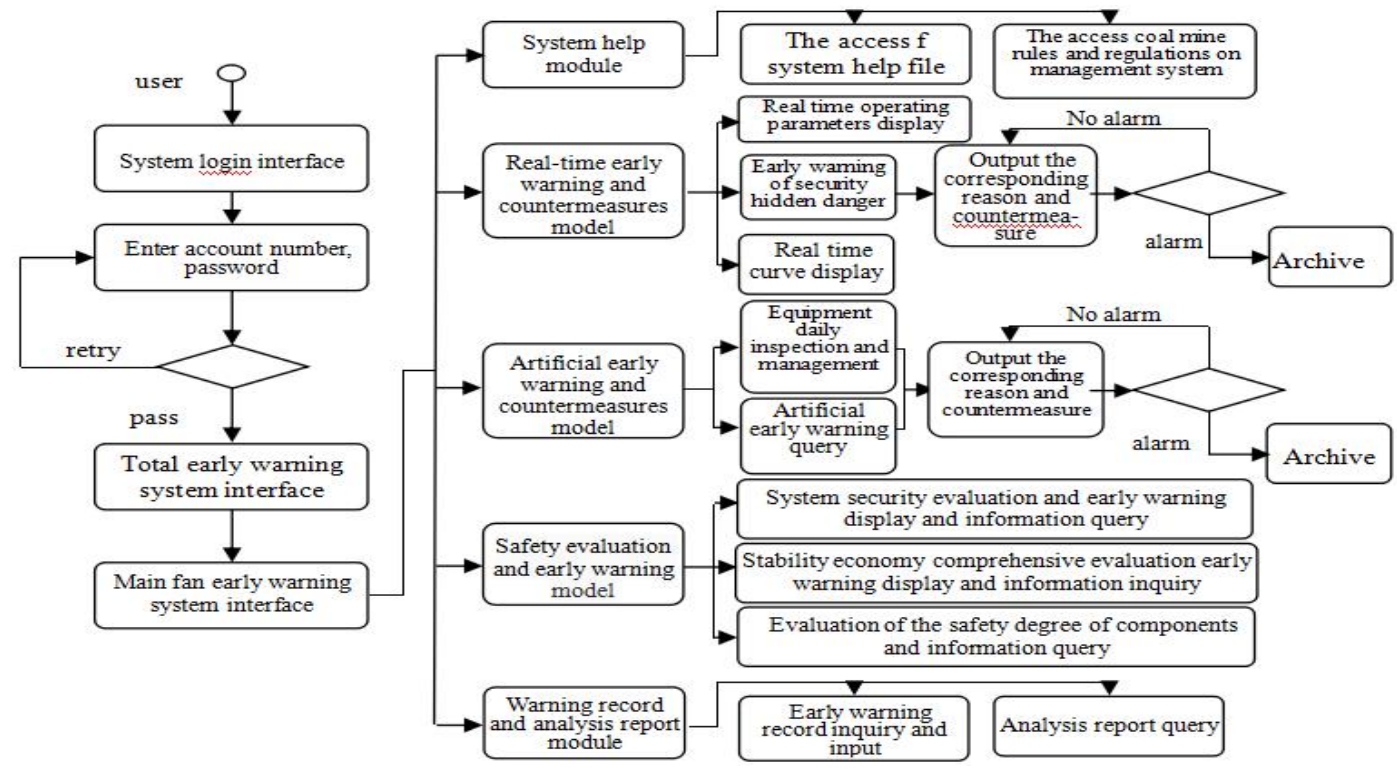

Figure 3. System user flow chart.

(1)The function of the security hidden danger warning and countermeasures display area is to display main ventilator running status in real time, when the main ventilation machine there are security risks and the corresponding positions will appear red and yellow warning display. Once when you click the warning area, it will gives a standby signal concerning the causes of the accidents and expert advice.

(2)The function of the early warning and countermeasures display area is to display the time, types, processing results and pin alarm time information of the main ventilator safety hidden danger.

(3)The function of safety evaluation and early warning display area is to calculate evaluation and early warning of the main ventilation machine running of the whole degree of safety, and expressed in an intuitive form of a histogram. The reliability of the system is calculated by using the monthly or annual early warning record statistical data, and the evaluation and early warning of the system security is based on the evaluation model. display area
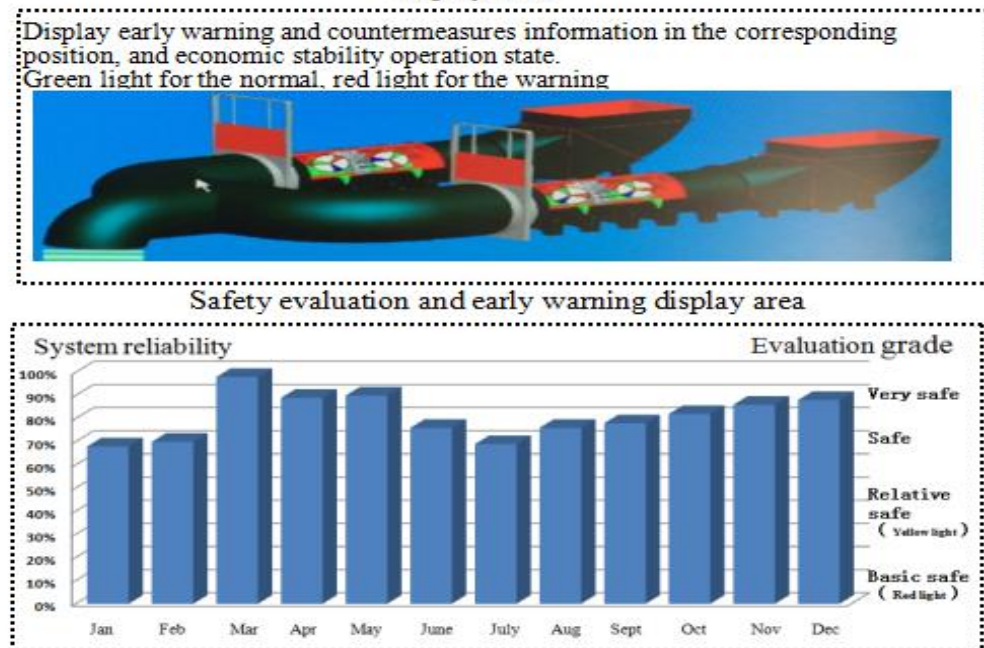

Function module menu bar
Early warning and countermeasures display area

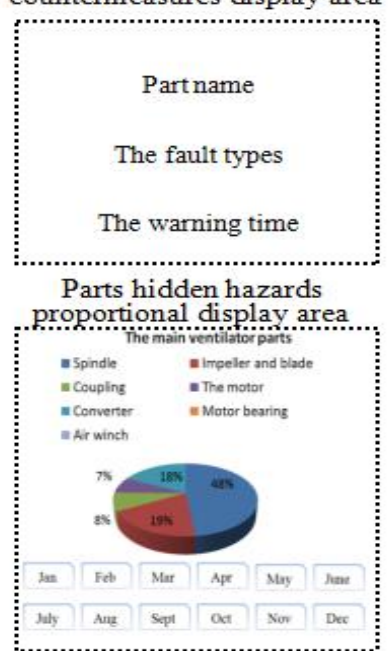

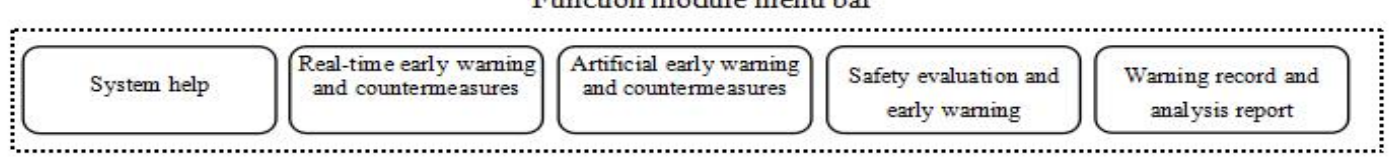

Figure 4. The design of main interface of the system. 
(4)The function of proportion of the risk components display area is to calculate the safety hidden danger degree of various parts of the main ventilator, and to express it in the form of pie chart. And to calculate parts' hitches according to the early warning record statistical data monthly or annually.

(5)The function of the module menu bar is to provide users the further use of the real-time warning and processing module, artificial warning and processing, safety evaluation and early warning module, and to query and browse the real-time operation parameters, case, model, documents and so on.

\section{System Software Implementation}

The system software is developed by using SQL, Server Java 2005 language. At present, it has been installed and operated in the Nanliang coal mine, and the operation effect is good, and the actual operation of the system software is shown in Fig. 5

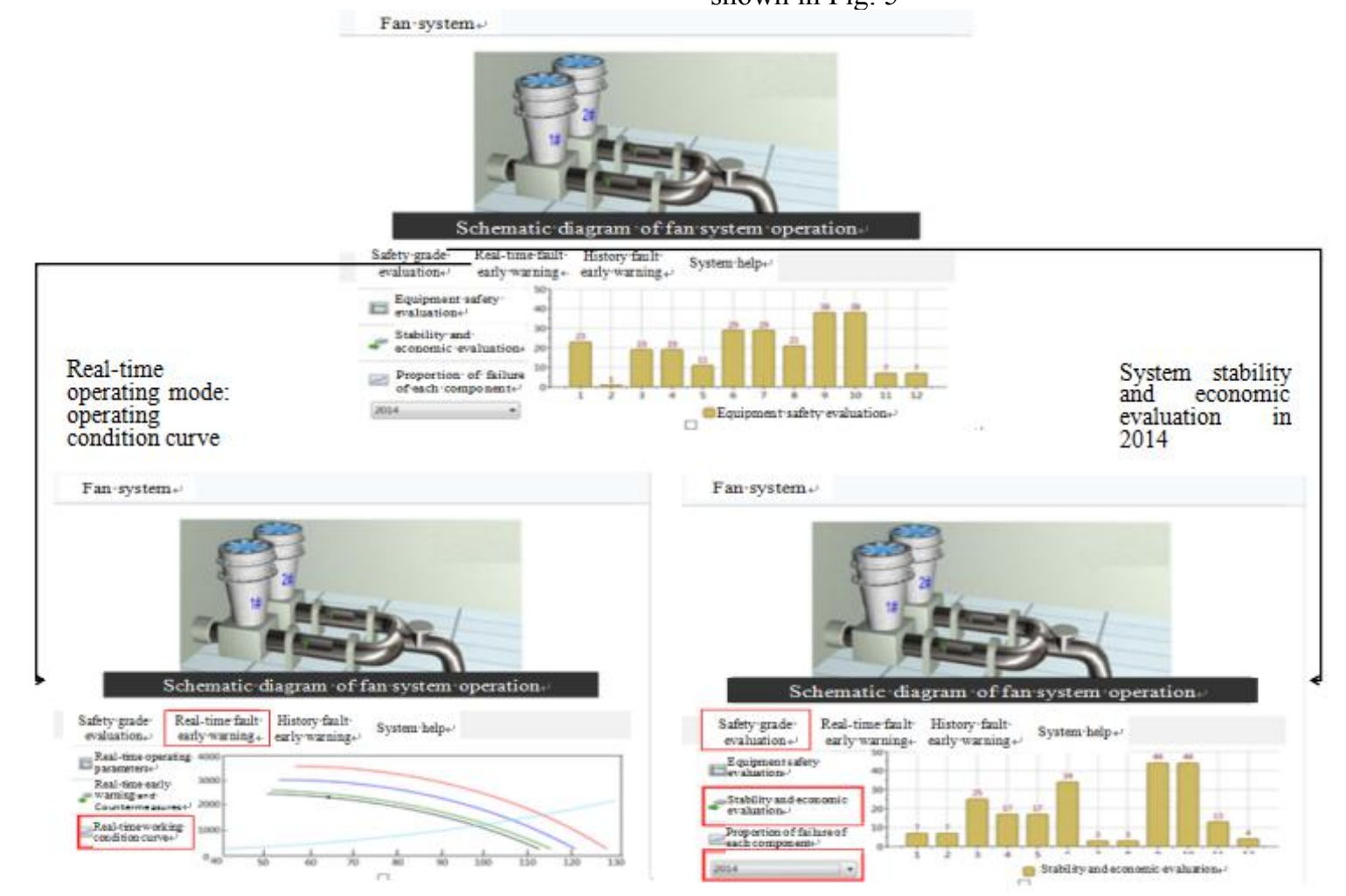

Figure 5 Running interface of the system software in mine site.

\section{CONCLUSION}

Based on the calculation and analysis of the the main ventilator's measured data during its operation, the maintenance records of the artificial daily inspection and a large number of fault cases, as well as the main types of security risks have been identified. By analyzing the monitoring parameters threshold, the symptom characteristic, assessment method and causes of their formation of main ventilator when various security hidden hazards arising, the system function model, information base system and the overall framework that satisfy the demands of early warning, assessment and disposal were established. The system software has been designed and developed to meet the demands of different users' decision support at all levels, and has been installed in the Nanliang coal mine, the purpose of providing expert intelligent decision support and informative management for safe operation of mine main ventilator has been achieved.

\section{REFERENCES}

[1] Yu D. Study on the mine ventilator detection and data processing technology. $[\mathrm{M}]$. D. dissertation. Henan: Henan Polytechnic University, 2009. (In Chinese)

[2] WU Chao, YANG Sheng-qiang, Fault diagnosis approach of local ventilation aystem in coal mines based on multidiscipli-nary technology [J]. Safety in Coal Mines, 2013, 44(2): 179-185.

[3] Yao Y, Zhang F. Main Ventilator Monitoring System Based on ZigBee wireless network [J].Colliery Mechanical \& Electrical Technology, 2014 (2):105-106. (In Chinese)

[4] He Y H. The research on main ventilator fault early warning monitoring system [J]. Coal Mine Machine, 2014, 35(9):279-281. (In Chinese)

[5] Gong X Y, Tao X L, Xue H. The establishment and development of mine local ventilation equipment troubleshooting information systems. Mining \& Processing Equipment, 2006(8):43-45. (In Chinese)

[6] Gong Xiaoyan, Xue He, Tao Xinli, et al. Fault Diagnosis Approach of Local Ventilation System in Coal Mines Based on Multidisciplinary Technology[J].Chinese Journal of Mining Sciences and Technology,2006(9):318 320. 